Sağlam, Y. / Journal of Yasar University, 2018, 13/52, 316-321

\title{
Fisher Hipotezi'nin Fourier Yaklaşımı ile Testi: Gelecek-11 Ülke Grubu Örneği
}

\author{
Fisher Hypothesis with Fourier Form: Evidence From Next-11 Countries
}

\author{
Yağmur SAĞLAM, Sinop Üniversitesi, Türkiye, yağmur.saglam@ sinop.edu.tr
}

Öz: Bu çalışma seçili Gelecek-11 ülkelerinde Fisher Hipotezi'nin varllğını Fourier Yaklaşımı ile analiz etmektedir. Bu amaçla 1995-2016 yıllarına ait yıllık verilerin durağanlı̆̆ı Karul (2016) tarafindan gelişstirilen kademeli kirılmalı panel birim kök testi ile sorgulanmuştır. Elde edilen bulgulara göre Endonezya ve Filipinlerde reel faiz oranı birim kök içermektedir. O halde Fisher Hipotezi bu iki ülke için reddedilmiștir. Dolaylsıyla beklenen enflasyon oranı birebir nominal faiz oranlarına yansımamaktadır ve reel faiz oranını da etkilemektedir. Onun dışında seçili diğer ülkelerde Fisher Hipotezi kabul edilmiştir.

Anahtar Sözcükler: Gelecek-11, Fourier Yaklaşımı, Panel Birim Kök Testi, Fisher Hipotezi,

Abstract: This study analyzes the existence of the Fisher Hypothesis in the selected Next-11 countries with the Fourier Approach. For this purpose, the stationary of the annual data for the period between 1995 and 2016 is interrogated by gradual-shifts panel stationary test developed by Karul (2016). According to the findings, the real interest rate in Indonesia and the Philippines includes unit root. The Fisher Hypothesis is then rejected for these two countries. Therefore, the expected inflation rate does not reflect the nominal interest rates and as well affects the real interest rate. In other selected countries, Fisher Hypothesis is accepted.

Keywords: Next-11, Fourier Approach, Panel Stationary Test, Fisher Hypothesis

\section{Giriş}

2001 yılında ünlü yatırım bankası Goldman Sachs, "BRICS', şeklinde ifade edilen bir kısaltmayı gelişmekte olan ülkelerin (Brezilya, Rusya, Hindistan, Çin, Güney Afrika Cumhuriyeti) küresel ekonomiye girişini vurgulamak adına ekonomi yazınına kazandırmıştır. "Emergence-Gelişen" kavramının arkasındaki fikir uluslararası bağlamda derinden bir değişim ve canlanmayı ifade ediyor olmasıdır. Bu kavramın ortaya çıkışıyla birlikte, yeni gelişen ülkeleri tanımlamak adına daha bir sürü ve kimi zaman belirsiz kriterlere sahip sınıflamalar denenmiştir (Daziano 2014: 5).

İşte bu kez de 2005 yılında yine Goldman Sachs grubu için çalışan İngiliz ekonomist Jim O’Neil tarafindan Gelecek-11 'Next Eleven' ülke grubu tanımlanmıştır. Bu ülkeler dünyanın gelecekteki en büyük ekonomileri arasında gösterilmiştir ve farklı ekonomik göstergelerden (makroekonomik istikrar, ticari açıklık ve yatırım politikaları, eğitim kalitesi, politik olgunluk vb.) oluşan bir N-11 raporu yayınlamıştır. İlk olarak sadece Bangladeş, Pakistan, Filipinler, Nijerya, Vietnam, Mısır, İran bu grupta yer alırken 2011 yılında O’Neill Meksika, Endonezya, Güney Kore ve Türkiye’yi de gruba eklemiştir.

Farklı coğrafyalarda yer alan bu ülkelerin ortak özellikleri yüksek ve artan nüfus oranları ile ekonomik potansiyelleridir. 1980 ve 2008 yılları arasında Pakistan en yüksek nüfus artış oranına sahip iken kişi başına düşen gelir miktarı bakımından en iyi durumda olan ülke Güney Kore'dir ve yine nüfus artış oranı en düşük ülkedir. Nüfus artış oranı Batılı ekonomilere göre yüksek olan bu ekonomiler büyük bir tüketici potansiyeline sahiptir. Bu nedenle orta vadede işletmelerin pazara sunabileceği mal ve hizmetler için potansiyel bir tüketici havuzunu ifade ederken yüksek büyüme oranları bu pazar hızla büyüyerek daha fazla müşteri potansiyeli yaratacağı anlamına gelmektedir (ALOnaizi ve Gahoum 2017: 54).

Örneğin; Cairns ve Meilke (2012), Gelecek-11 ve BRICS ülkelerinin aynı zamanda iyi birer tarım ürünleri pazarı olduğunu ifade etmektedir. Kurduğu ithal talep modeline göre bu ülkelerden bazıları düşük, orta ve yüksek gelirli ülkelerden daha farklı bir ithalat eğilimi göstermezken Çin, Hindistan, G. Kore, Endonezya ve Vietnam'ın artan gelir ve nüfus oranına paralel olarak tarım ürünlerine yaptığı harcama miktarı giderek artmaktadır. Labes (2015) ise diğer gelişmekte olan ülkeler gibi Gelecek-11 ülkelerinin de en büyük ticaret partnerinin Avrupa Birliği olduğunu ifade etmiştir. $\mathrm{Bu}$ nedenle gerek BRICs gerekse Gelecek-11 ülkeleri ile AB arasında ekonomik bir bağ oluşmak zorunda kalmıştır. Ayrıca AB küresel ekonomik krizden sonra meydana gelen her tür zorlukla başa çıkmak ve gelişmekte olan ekonomilerin artan önemini de kavramak zorunda kalmıştır. Gelecek-11 ülkeleri küresel ekonomide meydana gelen hızlı değişimlerin sadece Batılı ülkeleri değil yükselen yeni nesil milletleri de etkilediğinin kanıtıdır. Hatta Labes (2015) onları üçüncü dünya ülkelerinden yükselen, 'mahallede ki yeni çocuklar (new kids on the bloc)', betimlemektedir. Gelecek-11 fenomeninin göründüğünden daha fazlası olacağını, büyük resmi hayal etmemiz gerektiğini ifade etmektedir. 
Yukarıda da ifade edildiği ve kolayca anlaşılacağı gibi Gelecek-11 ülkeleri üzerine yapılacak her çalışma gelişmekte olan ülke ekonomilerinin küresel ekonomiye nasıl etki ettiği açısından önem taşımaktadır. Ayrıca alan yazınında bu grup üzerine yapılmış ampirik çalışma sayısı yok denilecek kadar azdır. Bu nedenle bu çalışmada Gelecek-11 ülkeleri için Fisher Hipotezi'nin geçerliliği analiz edilmiştir. Çalışmanın geri kalan kısmı iki bölümden oluşmaktadır. İlk kısım Fisher Hipotezi ve bu hipotezin sınanması amaçlı yapılan ampirik çalışmalara yer verirken; ikinci kısım veri, metodoloji ve uygulama bulgularına açıklık getirmektedir. Daha sonra elde edilen sayısal veriler sonuç kısmında iktisadi olarak yorumlanmaktadır.

\section{Fisher Hipotezi ve Ampirik Literatür}

Irving Fisher (1930)'e göre uzun dönemde beklenen enflasyon oranında meydana gelen bir değişme ile nominal faiz oranı arasında aynı yönde pozitif bir ilişki mevcuttur. Çünkü uzun dönemde ekonomi tam istihdamda dengeye gelecektir ve reel faiz oranları bu durumdan etkilenmemektedir. Modern Fisher denklemine göre nominal faiz oranı, reel faiz oranı ile beklenen enflasyonun toplamına eşittir (Fisher, 1961: 27);

$i_{t}=r_{t}+\pi_{t}^{e}$ veya $r_{t}=i_{t}-\pi_{t}^{e}$

Fisher Hipotezi ampirik olarak gerek gelişen gerekse gelişmekte olan ülkeler için pek çok kez test edilmiştir. Yukarıdaki (1) numaralı denkleme göre nominal faiz oranı ile beklenen enflasyon arasında eş-bütünleşik, uzun dönemli bir ilişki beklenmektedir.

Yapılan ilk çalışmalar Fama (1975), Nelson ve Schwert (1977) gibi değişkenlerin durağanlığını dikkate almamıştır. Sadece uzun ve kısa dönem faiz oranları arasındaki korelasyon önemsenmiştir. Daha sonra faiz oranı ve enflasyon oranı arasındaki eş-bütünleşik ilişki test edilmeye başlanmıştır. Bunlardan en bilinenleri Mishkin (1992), Evans ve Lewis (1995) ile Wallace ve Warner (1993)'tür. Değişkenler arasında uzun dönemli bir ilişki olduğunu bulmuşlardır. Daha sonraları Vektör Hata Düzeltme Mekanizması (VEC) analizleri popularite kazanmıştır. Örneğin; Crowder ve Hoffman (1996) ABD ekonomisi için, Weidman (1997) Almanya ve Wesso (2000) Güney Afrika'da Fisher Hipotezi'nin bu analizle geçerli olduğunu ifade etmektedir. Yapılan çalışmların bir kısmı ise Fisher Hipotezi’ni reddetmektedir. Koustas ve Serletis (1999), 11 OECD ülkesi için yaptıkları çalışmada Japonya dışında hiçbir ülke için ele alınan dönemde eş-bütünleşik ilişkiye rastlamamışlardır. Aynı şekilde Christopoulos ve Leon-Ledesma (2007), enflasyon ve faiz oranı değişkenleri arasında doğrusal olmayan biri ilişki olduğunu vurgulamıştır. Hatemi-J ve Irandoust (2007), Singapur, Avusturalya, Japonya ve Malezya' yı analiz ettikleri çalışmada Fisher etksinin genel olarak reddetmişlerdir.

Berument ve Jelassi (2002), 26 ülke için nominal faiz oranı ve enflasyon oranı arasındaki ilişkiyi test etmişlerdir. ARCH ve ARCH-LM testleri ile her ülke için farklı bir dönem analiz edilmiştir. 26 ülkeden 16'sında Fisher Hipotezinin tam (strong version) olarak geçerli olduğunu ifade etmektedirler.

Maghyereh ve Al-Zoubi (2006), gelişmekte olan (Arjantin, Türkiye, Güney Kore, Brezilya, Malezya, Meksika gibi) altı ülke için Fisher etkisini test etmiştir. Nominal faiz oranı ve enflasyon oranı serilerinin doğrusal olmayan bir trend içerdiğini varsaymaktadır. Parametrik olmayan Bierens (200) testini her bir ülke için farklı dönemlerde uygulamışlardır. Ampirik bulgulara göre tam Fisher etkisi bu ülkelerde varlığını göstermektedir. Rasyonel beklentiler varsayımıyla tutarlı olarak beklenen enflasyon oranı ile nominal faiz oranı arasındaki ilişki birebirdir yani gelişmekte olan ülkelerde para yanılsamasının varlığını yansıtmaktadır.

Bezanic (2013), Fisher Hipotezini Hırvatistan için durağanlık testleri, Johansen İz (Yapısal Kırılmalı), VECM tanı ve eş-bütünleme testleri ile analiz etmiştir. 1996-2012 yılların ait aylık verilerden elde edilen sonuçlar; Fisher Hipotezinin kısa dönemde kısmen, uzun dönemde tam anlamıyla kabul edildiğini belirtmektedir.

Arısoy (2013), çeyrekli veriler ile Fisher etkisinin geçerliliğini Türkiye için sorgulamıştır. Kalman Filtresine dayalı zamanla değişen parametreler yaklaşımı ile elde edilen bulgular 1987-2010 yılları arasında Fisher etkisinin zayıf forumunun geçerli olduğunu ayrıca para politikasının reel faiz oranlarını etkilemediğini çünkü enflasyon oranının nominal faiz oranındaki değişimleri kısmen elimine ettiğini ifade etmektedir.

Uçak ve diğerleri (2014), Çek Cumhuriyeti, Macaristan, Polonya ve Slovakya gibi yeni AB üyesi ülkelerden oluşan bir grup için Fisher etkisini analiz etmişlerdir. 1991-2011 dönemime ait ve OECD veri tabanından elde edilen aylık veriler Hatemi ve Hacker (2005) boosttrap yöntemi ile test edilmiştir. İlgili dönemde seçili ülkeler için yapısal kırılmalar varlığında Fisher etkisinin varlığı görülmektedir.

Köksel ve Destek (2015), Fisher Hipotezi'ni aylık veriler ile 2002-2014 dönemi için analiz etmişlerdir. Türkiye'de enflasyon oranları ve nominal faiz oranı arasında eş-bütünleşik bir ilişki olduğunu ettikleri bu çalışmada yapısal kırılmalı eş-bütünleşme analizinden yararlanmışlardır. VECM (Vektör Hata Düzeltme Modeli) Granger Nedensellik testinden elde edilen bulgular, kırılmalarında nominal faiz oranını etkilediğini vurgulamaktadır.

Lebe ve Özalp-Arda (2016), Türkiye için ARDL sınır testi ile Fisher Hipotezi’ni test etmişlerdir. 1970-2014 dönemine ait aylık verilerin (reeskont faiz oranı, mevduat faiz oranı ve para politikası faiz oranı gibi) analiz edildiği ampirik modele göre faiz oranı ve enflasyon oranı arasında eş-bütünleşik bir ilişki mevcuttur. Enflasyon oranı hem uzun hem de kısa dönemde faiz oranlarını pozitif yönde etkilemektedir. Öruç (2016), tam Fisher etkisini Türkiye üzerine yaptığ çalışmasında reddetmiştir. 1988-2014 dönemine ait çeyrekli veriler Engle-Granger, Johansen eş-bütünleşme testleri ile 
Dinamik EKK yöntemi ve Wald Testi ile analiz edilmiştir. Faiz oranları ve enflasyon serileri birim kök içermektedir. Uzun dönemde Fisher etkisi vardır.

Uyaebo ve diğerleri (2016), Fisher Hipotezi'nin geçerliliğini Nijerya için Gregory ve Hansen eş-bütünleşme testi ile analiz etmişlerdir. 1970-2014 yılları arasında (2005 yılı kırılma yılı olarak kabul edilmiş) nominal faiz oranı ve enflasyon arasında uzun dönemli bir nedensellik ilişkisi bulunmuştur. Kısa dönem nominal faiz oranı para politikası davranışını iyi karakterize eden bir göstergedir. Uzun dönemde zayıf Fisher etkisi mevcut iken kısa dönemde Fisher etkisi yoktur.

Caporale ve Alana (2017), Fisher Hipotezi'ni G-7 ülkeleri için test etmişlerdir. İlgili dönem standart I(1)-birinci fark1 durağan ve I(0)-düzeyde durağan şeklindeki klasik iki yönlü varsayımdan daha fazlasına dayalı olan kademeli bütünleşme ve eş-bütünleşmeye dayalı Robinson (1994) be Bloomfield (1973) yöntemleri ile test edilmiştir. Elde edilen sonuçlar nominal faiz oranı ve enflasyon oranı arasında pozitif yönde bir ilişki olduğunu ifade etmektedir.

\section{Fourier Yaklaşımı - Kademeli Kırılmalı Birim Kök Testi}

John Taylor (1989)'e göre birim kökün iktisadi anlamı makroekonomik değişkenlerde meydana gelen şokların kalıcı etkilerinin olması ve serinin zaman içerisinde ortalamasına dönememesidir. Ĕger bu dikkate alınmaz ise politika yapıcılar yanlış bir politika önerisinde ya da müdahalesinde bulunabilmektedir (Sağlam vd. 2016: 156). Bu yüzden yapısal kırılmalara (serinin rejiminde değişikliğe) neden olan bu şokların sayısının ve zamanının belirlenmesi önem taşımaktadır. Bu soruna yönelik ilk çözüm Becker vd. (2004) tarafından önerilmiş, ardından Enders ve Lee tarafından geliştirilmiştir.

Enders ve Lee (2004), yapısal kırılmaların tahmin edilemeyen sıklıkta ve yapısal formda olabileceğini varsayan bir birim kök testi geliştirmişlerdir. Amaçları mevcut birim kök literatüründe kabul görmüş olan 'seriler düzeyde veya trendde bir en fazla iki yapısal kırılmaya tabidir’’öngörüsünü (a priori) değiştirmektir. Çünkü bilinmeyen formlarda ve doğrusal olmayan deterministik terimlerin birim kökün varlığına olan etkisini kontrol etmek istemişlerdir.

Fourier yaklaşımının avantajları nelerdir (neden önemli)? Fourier fonksiyonu olarak adlandırılan bu yöntemle birlikte süreç, belirli kırılma tarihlerini veya kırılma formunu seçmek yerine (kırılma sayısı ve tarhini seçme sorunsalını elimine ediyor), modeli tahmin etmek için uygun frekans bileşeninin seçilmesine dönüştürülmüştür. Bu yüzden birim kök testinin kırılmalara izin vermesi özellikle modelin deterministik bileşeni için yumuşatılmış bir geçiş süreci tercih edilmektedir. Ayrıca bu yaklaşım yapısal kırılmaların (içsel veya dışsal şokların) yapısının bilinmediği durumlarda dahi doğru bir biçimde modellenmelerine ve bu sayede güvenilir, sapmasız sonuçlar elde edilmesine imkan sağlamaktadır. Bilinen diğer birim kök testlerinin çoğunda bu soruna bir çözüm getirilememekte ve yapısal kırılma tarihi ve sayısı dışsal olarak belirlenmekte ya da formu bilinmemektedir.

Enders ve Lee'nin geliştirdiği bu model kademeli kırılmalar için en iyi şekilde sonuç vermektedir. Geleneksel görüşün aksine (kukla değişken kullanmak gibi) yapısal kırılmaların panel veri setleri için nasıl modelleneceği konusunda ilk çalışma yine Becker vd. (2006) tarafından önerilen Fourier KPSS testidir. Daha sonra Fourier DF ve Fourier GLS birim kök testleri farklı kişiler tarafından yine panel veri analizleri için geliştirilmişstir.

$$
d_{i}(t) \cong a_{i 0}+a_{i k} \sin (2 \pi k t / T)+\beta_{i k} \cos (2 \pi k t / T)
$$

Yukarıda belirtilen 2 numaralı denklem Enders ve Lee (2012) tarafından geliştirilmiş olup tek frekans bileşeni (k) kullanıldığını ifade etmektedir. Çünkü çoklu frekans kullanımını serbestlik derecesini düşürdüğü için eleştirmektedirler. a_ikve $\beta$ _ikDicky-Fuller'ın varsayımının aksine doğrusal olmayan trendi ifade etmektedir.

2 numaralı denklemden yola çıkarak tek frekanslı veri yaratma sürecini şu şekilde tanımlanabilmektedir (Karul, 2016: $13)$;

$$
y_{i t}=\mu_{i}+b_{i} t+\gamma_{1 i} \sin (2 \pi k t / T)+\gamma_{2 i} \cos (2 \pi k t / T)+e_{i t}
$$

$e_{i t}$ hata terimini ifade etmektedir. 3 numaralı denklem ile ' $H_{0}: p_{i}=1, H_{1}: p_{i}<1$ ' serinin durağan olmadı̆̆ını yani birim kök içerdiğini ifade eden sıfır hipotezi ve alternatifi test edilmektedir. Fourier yaklaşımı $L M$ panel test istatistiğini kullanmaktadır. LM panel test istatistiği asimptotik ki-kare dağılımına sahip olup paneldeki her bir kesit için hesaplanmaktadır (Nazlıoglu vd., 2016: 173).

Bu çalışmada Fisher Hipotezi (reel faiz oranlarinin durağanlığı) sekiz 'Gelecek-11' ülkesi (Bangladeş, Mısır, Endonezya, Meksika, Nijerya, Filipinler, Güney Kore, Vietnam) için 1995-2016 yıllarını kapsayan bir dönemde test edilmiştir. 1995 yılı öncesine ait dönem ile Pakistan, Türkiye, İran veri kısıtı nedeniyle çalışmaya dahil edilememiştir. Bu çalışma ampirik yönü bakımından literatüre iki farklı katkıda bulunmaktadır. İlki Fisher Hipotezi’ni daha önce kademeli kırılmaları dikkate alarak test eden ve reel faiz oranlarının durağan olduğu (Irving Fisher'a göre 1 numaralı denklemde reel faiz oranları etkilenmemektedir o halde birim kök içermemesi gerekmektedir) varsayımı ile test eden bir panel veri analizi çalışmasının bulunmamasıdır. İkincisi "Gelecek-11" ülke grubu için Fisher Hipotezi daha önce hiç test edilmemiştir.

Yapısal kırılmaların kademeli birim kök testi ile analiz edilidiği bu çalışmada reel faiz oranı doğal logaritmik formu ile seçili ülkeler için Dünya Bankası, Dünya Gelişme Göstergeleri veri tabanından yıllık olarak elde edilmiştir. Frekans değerleri (single frequency) k=1,2,3 olarak seçilmiştir. Ayrıca uygulama kısmında Karul (2016) tarafından yazılan Gauss kodu tarafimca bu çalışmaya uyarlanmıştır. 
Tablo 1. Kademeli (Yumuşak)-Kırılmalı Birim Kök Testi Sonuçları

\begin{tabular}{|c|c|c|c|c|c|c|}
\hline Ülkeler & $\begin{array}{c}S \\
k=1\end{array}$ & $\begin{array}{c}S v e T \\
k=1\end{array}$ & $\begin{array}{c}S \\
k=2\end{array}$ & $\begin{array}{c}S v e T \\
k=2\end{array}$ & $\begin{array}{c}S \\
k=3\end{array}$ & $\begin{array}{c}S v e T \\
k=3\end{array}$ \\
\hline Bangladeş & $0.2186 * *$ & $0.0920 *$ & $0.8731^{*} *$ & $0.1412 * *$ & $0.9105 * * *$ & $0.1694 * *$ \\
\hline Misır & 0.0905 & 0.0223 & $0.6937 * *$ & 0.0816 & $0.7249 * * *$ & 0.1015 \\
\hline Endonezya & 0.0509 & 0.0421 & 0.0370 & 0.0376 & 0.1525 & 0.0347 \\
\hline Meksika & $0.1574 *$ & 0.0214 & $0.4175 *$ & 0.0813 & $0.5668 * *$ & 0.0923 \\
\hline Nijerya & 0.1180 & 0.0392 & $0.7647 * *$ & 0.1620 & $0.7233^{* * *}$ & $0.1641^{* *}$ \\
\hline Filipinler & 0.0644 & 0.0400 & 0.0666 & 0.0351 & 0.0356 & 0.0342 \\
\hline G. Kore & $0.3915 * * *$ & $0.0969 *$ & $0.7003 * *$ & $0.1765 * *$ & 0.1643 & $0.2557 *$ \\
\hline Vietnam & 0.0370 & 0.0214 & $0.3486 *$ & $0.2272 *$ & 0.3545 & $0.2326 *$ \\
\hline Panel İst. & 3.9518 & 3.7767 & 7.3913 & 4.7857 & 8.1903 & 5.1911 \\
p değgeri & 0.0000 & 0.0001 & 0.0000 & 0.0000 & 0.0000 & 0.0000 \\
\hline
\end{tabular}

S; sabit, S ve T; sabit ve trendli modele ait değerleri ifade etmektedir. *\% 1, ** \% 5, ***\% 10 düzeylerinde anlamlılı̆g 1 ifade etmektedir.Panel test istatistikleri Barlett Kernel kuralına göre elde edilmiştir, Kurozumi (2002). Olasılık (p) değerleri normal dağılıma sahiptir. Sabitli model için kritik değerler; k=1 frekansında kritik değerler, \% 1 için $0.1318, \%$ 5 için 0.1720 , \% 10 için 0.2699 'dur. k=2 frekansında kritik değerler, \% 1 için 0.3150 , \% 5 için $0.4152, \% 10$ için 0.6671 'dir. $\mathrm{k}=3$ frekansında kritik değerler, \% 1 için 0.3393 , \% 5 için 0.4480 , \% 10 için 0.7182 'dir. Sabit ve trendli model için kritik değerler; $\mathrm{k}=1$ frekansında kritik değerler, \% 10 için $0.0471, \% 5$ için $0.0546, \% 1$ için 0.0716 'dır. k=2 frekansında kritik değerler, \% 10 için $0.1034, \% 5$ için 0.1321 , \% 1 için 0.2022 'dir. $\mathrm{k}=3$ frekansında kritik değerler, \% 10 için 0.1141, \% 5 için 0.1423, \% 1 için 0.2103'dir (Becker vd., 2006: 389). Tablo 1 incelendiğinde Bangladeş ve Güney Kore için tüm frekans düzeylerinde kademeli kırılmaların kalıcı etkisi olduğunu ifade edebiliriz. Çünkü LM test istatistikleri, tablo kritik değerlerinden hem sabitli hem de sabit ve trendli model için büyük ve anlamlıdır. O halde reel faiz oranlarının durağan olmadığını (birim kök vardır) ifade eden boş hipotez reddedilmektedir, Fisher Hipotezi bu ülkelerde geçerlidir. Mısır, Meksika, Nijerya ve Vietnam'da ise farklı kırılma düzeyleri ve modeller için birim kökün varlığı reddedilmiştir. O halde Endonezya ve Filipinler hariç Fisher Hipotezi seçili Gelecek-11 ülkeleri için kademeli yapısal kırılmaların varlığında dahi geçerlidir.

\section{Sonuç}

Irwing Fisher kurduğu denklemde reel faizi sabit kabul etmektedir. Fakat bu varsayım ile Fisher sadece enflasyon ve nominal faiz oranlarının tek haneli rakamlarda seyrettiği ülkelerde geçerli olmaktadır. Çünkü Fisher Hipotezi ' beklenen enflasyon oranının nominal faiz oranına birebir yansımasıdır',

Dolayısıyla enflasyon oranında meydana gelecek bir değişim uygulamada yalnızca nominal faiz oranını değil reel faiz oranını da etkileyecektir. Reel faiz oranı bir risk algısıdır. Özellikle gelişmekte olan ülkelerde yatırımcılar için bir getiri göstergesidir. O halde reel faiz oranı artarsa risk algısı da artacak demektir. Gelecek-11 ülkelerinin 2005 yılında varsayıldığı gibi geleceğin en büyük ekonomileri arasında yer alması artan nüfus oranı ve dolayısıyla artan tüketici potansiyelinin (yeni pazarlar) yanısıra bu ülkelere yapılacak yatırım miktarı ve dolayısıyla faiz ile enflasyon oranlarının istikrarına da bağlıdır.

Bu ülkeler AB gibi tek elden bir para politikası uygulamadığı ve farklı coğrafyalarda farklı yapısal konjonktürler ile karşı karşıya kaldıkları için reel faiz oranının her birinde durağan olması beklenemez. Yapılan ampirik analize göre Endonezya ve Filipinlerde reel faiz oranı birim kök içermektedir. O halde Fisher Hipotezi bu iki ülke için reddedilmiştir. Dolayısıyla beklenen enflasyon oranı birebir nominal faiz oranlarına yansımamaktadır ve reel faiz oranını da etkilemektedir. Onun dışında seçili altı Gelecek-11 ülkesinde Fisher Hipotezi kabul edilmiştir. Çalışma bulguları bu bağlamda hem Hatemi-J ve Irandoust (2007) ile Uyaebo ve diğerleri (2016) hem de Uçak ve diğerleri (2014) tarafindan yapılan çalışmalardan elde edilen bulgular ile benzerlik göstermektedir. 


\section{KAYNAKÇA}

ALOnaizi, Bader, R., ve Gadhaoum, Yousr 2017. 'The Next 11: Emerging Investment Market', 1st International Conference on Advanced Research, ICAR, Manama, Bahrain. http://www.apiar.org.au 10.05.2018.

Arısoy, İbrahim, 2013. ' 'Testing for Fisher Hypothesis under Regime Shifts in Turkey: New Evidence from Time-Varying Parameters.' International Journal of Economics and Financial Issues, 3(2): 496-502.

Becker, Ralf, Enders, Walter ve Hurn, Stan, 2004. "A General Test for Time Dependence in Parameters.” Journal of Applied Econometrics, 19: 899-906.

Becker, Ralf, Enders, Walter ve Lee, Junsoo, 2006. 'A Stationarity Test in The Presence of An Unknown Number of Smooth Breaks." Journal of Time Series Analysis, 27: 381-409.

Berument, Hakan ve Jelassi, Mehdi, M. 2002. 'The Fisher Hypothesis: A Multi-Country Analysis.' Applied Economics, 34: 1645-1655.

Bezanic, Manuel, 2013. 'Testing the Fisher Effect in Croatia: An Empirical Investigation.' Economic ResearchEkonomska Istrazivanja, 26(1): 83-102.

Cairns, Alex ve Meilke, Karl, D. 2012. 'The Next-11 and the BRICs: Are They the Future Markets for Agrifood Trade', CATPRN Working Paper, April-03.

Caporale, Maria, G. ve Gil-Alana, Luis, 2017. 'Testing the Fisher Hypothesis in the G-7 Countries Using I(d) Techniques', DIW Berlin, Discussion Papers, 1667.

Christopoulos, Dimitris, K., Leon-Ledesma, Miguel, A. 2007. 'A Long-run Nonlinear Approach to the Fisher Effect." Journal of Money, Credit, and Banking, 39, 543-559.

Crowder, William, J. ve Hoffman, Dennis, L. 1996. 'The Long-run Relation Between Nominal Interest Rates and Inflation: The Fisher Equation Revisited." Journal of Money, Credit and Banking, 28: 102-118.

Daziano, Laurence, 2014. 'The New Wave of Emeging Countries, BENIVM', Fondapol Foundation For L'Innovation Politique, December, https://www.fondapol.org 08.05.2018.

Enders, Walter ve Lee, Junsoo, 2004. 'Testing For a Unit Root with A Nonlinear Fourier Function', Econometric Society, Far Eastern Meetings, https:/www3.nd.edu/ meg/MEG2004/Lee-Junsoo.pdf 15. 04. 2018.

Fama, Eeugene, F. 1975. 'Short-term Interest Rates as Predictors of Inflation.'” American Economic Review, 65: 269282.

Fisher, Irving, 1930. The Theory of Interest, Macmillan Co., New York, USA.

Hatemi-J, Aabdulnasser ve Irandoust, Manucheher, 2008. 'The Fisher Effect: A Kalman Filter Approach to Detecting Structural Change." Applied Economics Letters, 15: 619-624.

Karul, Çağın 2016. 'Esnek Fourier Fonksiyonlu Yeni Bir Panel Birim Kök Testi Önerisi ve OECD Örneği, Pamukkale Üniversitesi, Sosyal Bilimler Enstitüsü, Ekonometri Anabilim Dalı, Yayınlanmış Yüksek Lisans Tezi.

Koustas, Zisimos ve Serletis, Apostolos, 1999. ''On the Fisher Effect.', Journal of Monetary Economics, 44: 105-130.

Köksel, Bilge ve Destek, Mehmet, Akif, 2015. 'Türkiye Ekonomisinde Fisher Hipotezinin Test Edilmesi: 2002-2014 Dönemi Üzerine Bir Ampirik Analiz.’' Uluslararası Sosyal Araştırmalar Dergisi, 8(41): 1247-1253.

Kurozumi, Eiji, 2002. ' Testing for Stationarity with A Break.', Journal of Econometrics, 108 (1): 63-99.

Labes, Sebastian-Andrei, 2015. 'Beyond BRICS - An Emerging Markets Economic Analysis”, Alexandru Ioan Cuza University, Centre For European Studies, EURINT Proceedings.

Lebe, Fuat ve Özalp-Arda, Leyla, F. 2016. '’Fisher Hipotezi’nin Alternatif Faiz Oranları ile Türkiye Ekonomisi Açısından Analizi.’ Dokuz Eylül Üniversitesi İ̈BF Dergisi, 31(1): 95-122.

Maghyereh, Aktham ve Al-Zoubi, Haitham, 2006. 'Does Fisher Effect Apply in Developing Countries: Evidence From a Nonlinear Cotrending Test Applied to Argentina, Brazil, Malaysia, Mexico, South Korea and Turkey.' Applied Econometrics and International Development, 6(2): 31-46.

Mishkin, Frederic, S. 1992. 'Is the Fisher Effect for Real? A Reexamination of the Relationship Between Inflation and Interest Rates', Journal of Monetary Economics, 30: 195-215.

Nazlığlu, Şaban, Görmüş, Alper, N. ve Soytaş, Uğur, 2016. '’Oil Prices and Real Estate Investment Trusts (REITs): Gradual-shift Causality and Volatility Transmission Analysis.' Energy Economics, 60: 168-175.

Nelson, Charles, R. ve Schwert, William, G. 1977. 'Short-term Interest Rates As Predictors of Inflation: On Testing the Hypothesis that the Real Rate of Interest Is Constant.' American Economic Review, 67(3): 478-486.

Öruç, Erhan, 2016. '’Fisher Etkisi: Türkiye Üzerine Bir Uygulama.' Kastamonu Üniversitesi İIBF Dergisi, 13: $297-311$.

Sağlam, Yağmur, Egeli, Hüseyin A. ve Egeli, Pınar, 2017. “Gelişmiş ve Gelişmekte Olan Ülkelerde Ar\&Ge Harcamaları ve Ekonomik Büyüme Arasındaki İlişki: Panel Veri Analizi.” Sosyoekonomi Dergisi, 25(31): 149-165.

Weidmann, Jens, 1997. "New Hope for the Fisher Effect? A Reexamination Using Threshold Cointegration", Discussion Paper, Bonn: University of Bonn B-385: 1-25.

Wesso, Gilbert, R. 2000. "Long-term Yield Bonds and Future Inflation in South Africa: A Vector Error Correction Analysis." Quarterly Bulletin: South African Reserve Bank, 72-84.

Uçak, Harun, İlhan, Öztürk ve Aslan, Alper 2014. ' An Examination of Fisher Effect for Selected New EU Member States." International Journal of Economics and Financial Issues, 4(4): 956-959.

Uyaebo, Stephen, O. U., Yakubu, Bello A., Babatu, Omotosho, S., Karu, Suleiman, Satumari, Stephen, A., Raymond, Ogbuka, O., Balabare, Usman, F., Oluwaseun, Mimiko, D. 2016. 'Testing the Fisher Hypothesis in the Presence 
Sağlam, Y. / Journal of Yasar University, 2018, 13/52, 316-321

of Structural Breaks and Adaptive Inflationary Expectations: Evidence From Nigeria.' CBN Journal of Applied Statistics, 7(1b): 333-358. 